\title{
SEX DISCRIMINATION: EMPLOYMENT LAW AND PRACTICES by Arjun P.
} Aggarwal (Markham, Ont.: Butterworths, 1994).

In Sex Discrimination: Employment Law and Practices, A.P. Aggarwal provides a thorough, up-to-date and very readable review of jurisprudence from the courts and human rights and labour arbitration tribunals relating to various forms of sex discrimination and other forms of discrimination in the employment context. A great many cases are presented involving the application of human rights laws, the Charter of Rights and Freedoms, ${ }^{\prime}$ and the provisions of collective agreements. The cases are categorized and presented by the work-related issues to which they pertain, such as "Dismissal Because of Pregnancy" and "Absence From Work Due to Pregnancy," rather than by particular statutory provisions, so that the reader is provided with an array of legal approaches that may be appropriate to a particular practical problem. As a consequence of all of these qualities, the book is an interesting read and a useful research tool for legal practitioners dealing with the problems presented.

The title of the book is somewhat misleading, as the problems presented in the book go beyond the scope of sex discrimination in some aspects and do not cover the full breadth of the topic in others. For instance, sexual harassment, a major aspect of employment discrimination, is not covered because the author has dealt with this topic separately in his earlier book, Sexual Harassment in the Workplace. ${ }^{2}$ On the other hand, other forms of discrimination based on marital status, family status and sexual orientation, which the author describes as "colloquially" related to sex, are included.

The book begins with a brief explanation of the basic forms of discrimination, namely: direct discrimination; indirect or adverse effect discrimination; and systemic discrimination. These concepts are revisited in the following chapters dealing with discrimination based on gender, discrimination resulting from height, weight and grooming requirements, and discrimination based on pregnancy, marital or family status and sexual orientation. Regarding each form of discrimination, issues arise relating to the existence of discriminatory conduct (i.e., has the employer acted "on the basis" of sex or in a way that has an adverse impact upon women?) and its defensibility (i.e., is gender a reasonable condition for particular employment or would the accommodation of an employment rule that adversely affects women cause undue hardship?). The defences are referred to incidentally in the discussion of the case law dealing with the different forms of discrimination, but are not subjected to analytical treatment until later in the book. This division ignores the fact that while the existence of and defences to discriminatory conduct are theoretically distinct, the real impact of the law upon employment practices depends on both. Furthermore, problems arise with this division because once certain definitional issues have been conclusively established, such as whether discrimination based upon pregnancy is the legal and functional equivalent of sex discrimination, the real issues in the subsequent jurisprudence relate to the extent of the prohibition of pregnancy-based discrimination, which is dependent on the scope 
of the applicable defence. The division of the book into definitional and defensive issues in its treatment of pregnancy-based discrimination results in too much attention being paid to the first issue at the expense of the latter. The point that discrimination based on pregnancy constitutes sex discrimination is made repeatedly, while other issues are glossed over. For example, the issue of when, if ever, actual or potential absence from a job due to pregnancy may be considered by an employer in making decisions whether to hire, fire or promote is dealt with only cursorily. Reference is made to cases in which this issue was raised, but there is no analysis of the standard of proof to be applied to an employer arguing that continuous presence on the job is a reasonable job requirement. Similarly, the issue of job risks associated with pregnancy is raised in a number of cases, but the degree of risk or the responsibility for assessing it are not analyzed. The author ignores any discussion regarding what an employer would have to show under Canadian law to establish non-pregnancy or even nonfertility as a reasonable job requirement.

The later chapters dealing with defences to discrimination, set out the general legal principles and provide a number of pertinent applications. Unfortunately, in some instances, these chapters repeat points earlier made (e.g., that mere preferences of the employer, customers, or co-workers cannot justify discrimination), and in other instances leave unanswered questions, such as those pertaining to pregnancy-based discrimination.

The chapter on discrimination based on sexual orientation reviews issues that are currently being litigated, namely the relationship of this form of discrimination and discrimination based on marital status (where benefits that would be available to a heterosexual spouse or common law spouse are denied to the partner of a homosexual person) and whether the Charter can be used to challenge human rights laws and other legislation that exclude protection or benefits to homosexuals or their partners. In this part of the book, as in others, the coverage of the case law is very thorough and up to date. In this context, as in others, these issues beg for a point of view. However, the author's approach is descriptive and not prescriptive or even predictive. The conflicting decisions and conflicting signals provided by the courts and tribunals are carefully explained. The author, without predicting or advocating any particular position, concludes that the answers to the legal issues posed in this context are uncertain and may be subject to change. While this descriptive approach does not detract from the book's usefulness as a research tool, greater efforts in this regard may have made the book more intellectually challenging and increased its long term value.

The same approach is taken in the chapter on reasonable accommodation. Again, the jurisprudence is described extensively. The author also provides a useful summary of the requirements of accommodation as they affect employers, unions and complainants. Unfortunately, the author's analysis ends there when it could have continued. For instance, some consideration of the implications of the duty of accommodation in terms of women's issues in the workplace would have provided a valuable addition. Reasonable accommodation issues which have tended to arise in the context of religious or disability-based discrimination could have been addressed. As well, only a couple of cases discuss the accommodation of women's needs related to pregnancy and child 
care. Furthermore, the author could have examined the question of whether the duty of reasonable accommodation has the potential to require significant workplace changes to meet women's concerns about balancing employment and family obligations. While necessarily speculative, a discussion of this issue would be of great relevance to the persons whom the author seeks to address, namely lawyers, employers, human resource managers, affirmative action and equal opportunity administrators, union representatives, women's organizations, and teachers of human rights and women's issues.

The author's hope that this book will be useful for non-lawyers as well as lawyers, and for teaching purposes as well as professional purposes, may not be fully realized. Only the last chapter, "A Guide for Non-discriminatory Hiring Policies and Practices," is clearly directed to those involved in the practical aspects of employment. With regard to the rest of the book, the detailed coverage of case law that makes the book useful to lawyers limits its value to laypersons. While summaries are provided at the end of each chapter, much of the detail is unnecessary and perhaps confusing to a non-legal reader. For example, there is quite extensive coverage of now-overruled decisions on pregnancy-based discrimination ${ }^{3}$ and on the duty of reasonable accommodation. ${ }^{4}$ On one hand, this examination of the development of the law provides a useful context for legal research. However, on the other hand, this examination results in the author taking quite some time to explain the current state of the law in the chapters dealing with those issues. One presumes that employers and human resource managers would desire an up-to-date assessment of their obligations in a more efficient and concise manner. As well, the book's usefulness as a teaching tool is limited. While it may be an appropriate resource for specialized legal courses, for many courses there would be both too much and too little information provided. That is, the amount of jurisprudence covered would be more than needed. On the other hand, the lack of effort to go beyond the current case law means that the book does not provide its readers with a good springboard for discussion. This, however, should not detract from the real strength of the book in what is likely to be its primary application, which is as a reference source for legal practitioners dealing with cases of sex discrimination in employment.

June Ross

Assistant Professor

Faculty of Law

University of Alberta

3 Bliss v. Can. (A.G.), [1979] I S.C.R. 183.

$4 \quad$ Bhinder v. C.N.R., [1985] 2 S.C.R. 561. 